\title{
Blood pressure and glaucoma: At the crossroads between cardiology and ophthalmology
}

\author{
Janusz Skrzypecki ${ }^{1}$, Marcin Ufnal ${ }^{1}$, Jacek P. Szaflik ${ }^{2}$, Krzysztof J. Filipiak ${ }^{3}$ \\ ${ }^{1}$ Department of Experimental Physiology and Pathophysiology, Laboratory of Center \\ for Preclinical Research, Medical University of Warsaw, Poland \\ ${ }^{2}$ Department of Ophthalmology, SPKSO Ophthalmic Hospital, \\ Medical University of Warsaw, Poland \\ ${ }^{3} 1^{\text {st }}$ Chair and Department of Cardiology, Medical University of Warsaw, Poland
}

\begin{abstract}
Glaucoma is an optic nerve neuropathy of undetermined cause. Although many mechanisms are thought to be involved in the development and progression of the disease, only an increased intraocular pressure has been established as a clinically significant modifiable risk factor. Nevertheless, up to $40 \%$ of patients develop glaucoma without evidence of increased intraocular pressure.

Ample evidence suggests that alterations in the control of arterial blood might negatively affect optic nerve function. However, evidence-based guidelines on the management of arterial blood pressure in glaucoma patients are lacking.

Regrettably, intraocular pressure is generally not included as a secondary end-point in clinical trials on arterial hypertension. Considering the relative simplicity of intraocular pressure measurements and large number of patients included in hypertension studies, the benefits of including intraocular pressure as a secondary end-point could be of a great value for improving care for glaucoma patients. Therefore, closer collaboration between cardiologists and ophthalmologists is needed. (Cardiol J 2019; 26, 1: 8-12)
\end{abstract}

Key words: blood pressure, intraocular pressure, glaucoma, hypertension

\section{Introduction}

Glaucoma is a progressive optic nerve neuropathy [1]. It is estimated that by 2040 at least 112 million people will be diagnosed with glaucoma worldwide [2]. Increased intraocular pressure (IOP) is the only modifiable glaucoma risk factor which has been well established in clinical practice [1]. Pharmacotherapy, laser or surgical procedures are utilized to lower IOP and prevent deterioration of visual field defects [1]. However, up to $40 \%$ of patients develop glaucomatous neuropathy without any evidence of increased IOP [3]. This observation prompted research into alternative causes of optic nerve damage and abnormal level of arterial blood pressure $(\mathrm{ABP})$ - both too low and too high, was proposed as a possible risk factor [4]. Nevertheless, ophthalmologists are still far from evidence-based management of ABP in glaucoma patients.

In contrast, cardiologists have well established preferred practice patterns on the management of hypertension [5]. The most recent update of these guidelines recommends systolic blood pressure (SBP) between 120 and $129 \mathrm{mmHg}$ as a treatment goal in majority of high-risk patients [5]. Although the SPRINT study proved that a low ABP target significantly decreases mortality, and an intensified approach did not remain without side effects [6]. Acute kidney failure or syncope were reported by SPRINT investigators [6]. Interest-

Address for correspondence: Janusz Skrzypecki, MD, PhD, Department of Experimental Physiology and Pathophysiology, Medical University of Warsaw, ul. Banacha 1B, 02-097 Warszawa, Poland, tel: +48 22116 6195, fax: +48 225720734 , e-mail: jskrzypecki@wum.edu.pl

Received: 12.12.2018～Accepted: 3.01.2019 
ingly, although a growing body of evidence shows a close link between glaucoma and ABP, eye-related end-points were not included in the study $[4,6]$. Firstly, information could been have gained herein, on the impact of intensive lowering of ABP on the progression of optic neuropathy. Secondly, subanalyses could have revealed whether any antihypertensive drugs should be preferred in patients with glaucoma.

Considering that both hypertension and glaucoma pose a major public health challenge, a closer collaboration between cardiology and ophthalmology could bring cost-effective solutions to many unresolved questions and significantly improve patient care.

Summarized here is the current state of knowledge on the relationship between ABP and IOP. Furthermore, this study shows how landmark trials on hypertension could have benefitted patient care in ophthalmology.

\section{Blood pressure and glaucoma}

\section{High blood pressure and glaucoma}

Large epidemiological studies show that ABP positively correlates with IOP. Beaver Dam Eye study reported an $0.21 \mathrm{mmHg}$ increase in IOP for every $10 \mathrm{mmHg}$ increase in SBP [7]. Similar correlation was shown by Egna-Neumarkt study $-0.24 \mathrm{mmHg}$ IOP change per $10 \mathrm{mmHg}$ increase in SBP [8].

The Blue Mountains Eye Study suggested that hypertension itself might be a risk factor for glaucoma, regardless of ABP and IOP correlation [9]. Additionally, data from the British General Practitioner Research Database and studies by Horwitz et al. suggest that patients with glaucoma are more often diagnosed with hypertension than the general population $[10,11]$.

However, the aforementioned observations lack a sound mechanistic explanation. On the one hand, it is hypothesized that an increased capillary pressure in the ciliary body translates into higher IOP [4]. On the other hand, fluctuations in IOP might depend on a common humoral background of IOP and ABP control [12]. As hypertension induces atherosclerosis and impairs vascular autoregulation, some authors propose that it negatively affects blood supply to the optic nerve [13]. The latter hypothesis may explain observations of a higher prevalence of glaucoma in patients with systemic hypertension, irrespective of an ABP and IOP relationship [9].

\section{Low blood pressure and glaucoma}

Interestingly, some research contradicts studies claiming harmful effects of hypertension on the optic nerve. Recent analysis of the Maracaibo Aging Study showed that patients with hypertension have a lower risk of developing glaucoma [14]. What is more, it is hypothesized that a low $\mathrm{ABP}$ might accelerate progression of optic nerve neuropathy. Indeed, the Baltimore Eye Survey revealed that low office diastolic blood pressure (DBP) correlates with the prevalence of the optic neuropathy [15].

To further explain the relationship between low ABP and glaucoma progression, a parameter called ocular perfusion pressure (OPP) was introduced [16]. OPP is defined as the difference between either SBP or DBP and IOP. It is believed that OPP better reflects vascular supply to the optic nerve head than an ABP value alone [17]. Although some argue that better correlation of OPP with the optic neuropathy reflects only an increased level of IOP, studies which adjusted the results for IOP seem to contradict these remarks [18, 19].

More detailed insight into a relationship between glaucoma and low ABP was provided along with the introduction of a $24 \mathrm{~h}$ ambulatory blood pressure measurement (ABPM). It has been shown that a nocturnal decrease of mean $\mathrm{ABP}$ of at least $10 \mathrm{mmHg}$ was a predictor of glaucoma progression [20]. These findings were also supported by a recent meta-analysis which showed that a dipping pattern, defined as a nocturnal drop of ABP of more than $10 \%$, correlates with glaucoma progression [21]. Nevertheless, it is of note that the abovementioned cut-off values for nocturnal ABP drop, are well within a normal range reported for a population [22].

In contrast, more recent reports, as Maracaibo Aging Study, suggest that it is not the physiological nocturnal hypotension that triggers optic nerve damage, but rather the non-physiological overdipping pattern of more than 20\% [14]. Similar findings were presented by Pillunat et al. [23], who suggested that normotensive (but not hypertensive) patients with an over-dipping pattern of $\mathrm{ABP}$ have an increased risk of glaucoma progression.

Considering mechanisms of vascular autoregulation it might be puzzling to expect that even a physiological drop of ABP leads to the optic nerve ischemia. However, this chain of events reflects an impaired vascular regulation in glaucoma patients [24]. Under physiological conditions, in response to a drop of ABP, muscular arteries dilate and pro- 
vide a sufficient nutritional supply to the target organs [25]. However, in the setting of an increased baseline vascular tone, as reported in glaucoma, autoregulation might be ineffective [24].

\section{Antihypertensive therapy and glaucoma}

Conflicting conclusions also come from studies focused on a link between glaucoma and systemic antihypertensive treatment. Thessaloniki Eye Study showed that treatment with antihypertensive drugs, adjusted for a level of blood pressure, is associated with a more pronounced progression of glaucoma [26]. In contrast, Horwitz et al. [11] proves that although systemic hypertension is associated with an increased prevalence of glaucoma, onset of the optic nerve neuropathy is delayed by an intake of antihypertensive drugs.

Furthermore, analyses focused on specific drug classes showed that treatment with calcium channel blockers positively correlates with the prevalence of glaucoma, whereas administration of beta-blockers might be protective [27, 28].

Finally, it has been also proposed that nocturnal (before sleep) administration of antihypertensive medication affects optic nerve function to a greater extent in comparison to other times of the day [29].

\section{Landmark hypertension clinical trials in the XXI century}

According to the updated guidelines on systemic hypertension [30], it is estimated that around $40 \%$ of adults in the developed countries will be eligible for an ABP lowering treatment [30]. Furthermore, de Moraes et al. [31] reckons that at least $0.8 \%$ of people aged 40 and over will be diagnosed with both hypertension and glaucoma. Considering these estimates, it is of paramount importance to collect information on the relationship between hypertension or antihypertensive treatment and glaucoma. Regrettably, none of the landmark studies on hypertension assessed IOP or optic nerve function as a secondary end-point. Herein, the present study reveals how these trials could have improved patient care in ophthalmology.

\section{SPRINT}

The Systolic Blood Pressure Intervention Trial (SPRINT) was a double-blinded, controlled study which randomized high-risk hypertensive patients to intensive and standard treatment strategies with an SBP target of $120 \mathrm{mmHg}$ and $140 \mathrm{mmHg}$, respectively [6]. It showed that lowering SBP below $120 \mathrm{mmHg}$ might be of significant benefit to some hypertensive patients [6]. However, the study showed that although low ABP decreases mortality, it leads to some non-negligible systemic side effects and compels closer surveillance over this particular group of patients. The SPRINT trial reported that intensified treatment leads to an increased number of hypotensive episodes, syncope, acute kidney failure or electrolyte abnormalities [6]. Nevertheless, although there is a strong evidence that excessive $\mathrm{ABP}$ lowering has an effect on the optic nerve [20], no sub-analysis of the study addressed glaucoma progression as an adverse event of the SPRINT trial. Firstly, inclusion of eye related end-points in the SPRINT study with a follow-up of more than 3 years might have shown whether ABP values correlate with IOP. Secondly, sub-analyses could have revealed whether any group of antihypertensive drugs might be more favorable in terms of IOP in patients with hypertension. Finally, a large number of participants (more than 9000) and high co-occurrence of glaucoma and hypertension would permit insight into the effect of intensified hypertension treatment on the progression of the optic neuropathy. Interestingly, although ABPM studies performed on SPRINT trial participants confirmed lower ABP in the intensive treatment group, they showed no effect of the treatment on a $24 \mathrm{~h}$ pattern of ABP [32]. This analysis could add some merit to the conflicting discussion whether low ABP, without a nocturnal over-dipping pattern, leads to the optic nerve damage.

\section{Renal denervation clinical trials}

SYMPLICITY I, II and III renal denervation trials were aimed at patients with treatment resistant hypertension defined as an ABP over 140/90 $\mathrm{mmHg}$ despite treatment with at least 3 antihypertensive drugs, including a diuretic [33-35]. Although these studies did not show any advantage of renal denervation over pharmacotherapy, they did prove patient safety for the procedure [33-35]. SPYRAL HTN-OFF, which followed, showed that renal denervation might offer a viable antihypertensive management for patients who are not using ABP lowering medication [36]. The effectiveness of renal denervation is mechanistically tied to sympathetic nervous system inhibition [33]. Considering that non-selective beta-blockers are utilized to lower IOP, it could be hypothesized that renal denervation could simultaneously decrease ABP and IOP [37], thus offering a viable alternative to pharmacotherapy in patients with both glaucoma 
and hypertension. However, no sub-analyses on IOP were performed in multiple renal denervation studies performed worldwide. This analysis would help to assess the influence of the sympathetic nervous system on IOP regulation, and would be even more interesting considering that adrenaline drops, which were historically used to lower IOP [38], have now been replaced by beta-blockers.

\section{Perspectives $-\mathbf{2 4}$ hour ocular volume monitoring}

A contact lens sensor (Triggerfish, Sensimed, Switzerland) dedicated for monitoring of $24 \mathrm{~h}$ ocular volume pattern, which correlates with intraocular pressure changes, has recently been approved as a medical device in Europe and the United States [39]. In the setting of research into $\mathrm{ABP}$ and IOP correlation, Triggerfish appears to be a far more robust tool compared to current gold standard of IOP measurement, i.e. Goldmann applanation tonometry. Triggerfish records data for 30 s every 5 min over 24 h [39]. Furthermore, it allows measurements in habitual body positions and is the only device that facilitates the recording of IOP-related parameters during sleep [39]. Considering the aforementioned features and relative ease of fitting the sensor, its utilization could bring valuable information into discussion on the ABP and IOP relationship. However, its broad application is currently limited by the high cost, which is estimated at $\$ 700$ USD per one $24 \mathrm{~h}$ measurement [40].

\section{Conclusions}

Although elevated IOP is currently considered as the only treatable risk factor of glaucoma, many patients develop the disease despite normal IOP [1]. Therefore, it is of paramount importance to identify and precisely describe other modifiable risk factors of optic nerve neuropathy.

A growing body of research shows that $\mathrm{ABP}$ has a strong effect on IOP or a risk of glaucoma. Nevertheless, analysis of current knowledge brings inconclusive results regarding an evidence-based approach to ABP management in glaucoma patients.

The present study propozes that inclusion of IOP and assessment of the optic nerve function as secondary end-points in clinical trials on hypertension might deliver valuable data for a multifactorial approach to glaucoma.

Conflict of interest: None declared

\section{References}

1. Weinreb RN, Aung T, Medeiros FA. The pathophysiology and treatment of glaucoma: a review. JAMA. 2014; 311(18): 1901-1911, doi:10.1001/jama.2014.3192, indexed in Pubmed: 24825645.

2. Tham YC, Li X, Wong TY, et al. Global prevalence of glaucoma and projections of glaucoma burden through 2040: a systematic review and meta-analysis. Ophthalmology. 2014; 121(11): 2081-2090, doi: 10.1016/j.ophtha.2014.05.013, indexed in Pubmed: 24974815.

3. Klein B, Klein R, Sponsel W, et al. Prevalence of glaucoma. he Beaver Dam Eye Study. Ophthalmology. 1992; 99(10): 14991504, doi: 10.1016/s0161-6420(92)31774-9.

4. He Z, Vingrys AJ, Armitage JA, et al. The role of blood pressure in glaucoma. Clin Exp Optom. 2011; 94(2): 133-149, doi: 10.1111/j.1444-0938.2010.00564.x, indexed in Pubmed: 21255075 .

5. Williams B, Mancia G, Spiering W, et al. 2018 Practice guidelines for the management of arterial hypertension of the European Society of Hypertension (ESH) and the European Society of Cardiology (ESC). Blood Press. 2018; 27(6): 314-340, doi: 10. 1080/08037051.2018.1527177, indexed in Pubmed: 30380928.

6. Wright JT, Williamson JD, Whelton PK, et al. A randomized trial of intensive versus standard blood-pressure control. N Engl J Med. 2015; 373(22): 2103-2116, doi: 10.1056/NEJMoa1511939, indexed in Pubmed: 26551272.

7. Klein BEK, Klein R, Knudtson MD. Intraocular pressure and systemic blood pressure: longitudinal perspective: the Beaver Dam Eye Study. Br J Ophthalmol. 2005; 89(3): 284-287, doi: 10.1136/bjo.2004.048710, indexed in Pubmed: 15722304.

8. Bonomi L, Marchini G, Marraffa M, et al. Vascular risk factors for primary open angle glaucoma: the Egna-Neumarkt Study. Ophthalmology. 2000; 107(7): 1287-1293, indexed in Pubmed: 10889099.

9. Mitchell P, Lee AJ, Rochtchina E, et al. Open-angle glaucoma and systemic hypertension: the blue mountains eye study. J Glaucoma. 2004; 13(4): 319-326, indexed in Pubmed: 15226661.

10. Langman MJS, Lancashire RJ, Cheng KK, et al. Systemic hypertension and glaucoma: mechanisms in common and co-occurrence. Br J Ophthalmol. 2005; 89(8): 960-963, doi: 10.1136/ bjo.2004.053397, indexed in Pubmed: 16024843.

11. Horwitz A, Klemp M, Jeppesen J, et al. Antihypertensive medication postpones the onset of glaucoma: evidence from a nationwide study. Hypertension. 2017; 69(2): 202-210, doi: 10.1161/HYPERTENSIONAHA.116.08068, indexed in Pubmed: 27920127.

12. Skrzypecki J, Grabska-Liberek I, Przybek J, et al. A common humoral background of intraocular and arterial blood pressure dysregulation. Curr Med Res Opin. 2018; 34(3): 521-529, doi: 10.1080/03007995.2017.1415203, indexed in Pubmed: 29219620.

13. Sommer A, Tielsch J. Blood pressure, perfusion pressure, and open-angle glaucoma. Arch Ophthalmol. 2008; 126(5): 741; author reply 741-741; author reply 742, doi: 10.1001/ /archopht.126.5.741-a, indexed in Pubmed: 18474799.

14. Melgarejo JD, Lee JH, Petitto M, et al. Glaucomatous Optic Neuropathy Associated with Nocturnal Dip in Blood Pressure: Findings from the Maracaibo Aging Study. Ophthalmology. 2018; 125(6): 807-814, doi: 10.1016/j.ophtha.2017.11.029, indexed in Pubmed: 29310962.

15. Sommer A, Tielsch JM, Katz J, et al. Relationship between intraocular pressure and primary open angle glaucoma among white 
and black Americans. The Baltimore Eye Survey. Arch Ophthalmol. 1991; 109(8): 1090-1095, indexed in Pubmed: 1867550.

16. Gherghel D, Orgül S, Gugleta K, et al. Relationship between ocular perfusion pressure and retrobulbar blood flow in patients with glaucoma with progressive damage. Am J Ophthalmol. 2000; 130(5): 597-605, indexed in Pubmed: 11078838.

17. Zheng Y, Wong TY, Mitchell P, et al. Distribution of ocular perfusion pressure and its relationship with open-angle glaucoma: the singapore malay eye study. Invest Ophthalmol Vis Sci. 2010; 51(7): 3399-3404, doi: 10.1167/iovs.09-4867, indexed in Pubmed: 20164462.

18. Levine RM, Yang A, Brahma V, et al. Management of blood pressure in patients with glaucoma. Curr Cardiol Rep. 2017; 19(11): 109, doi: 10.1007/s11886-017-0927-x, indexed in Pubmed: 28929290.

19. Memarzadeh F, Ying-Lai M, Chung J, et al. Blood pressure, perfusion pressure, and open-angle glaucoma: the Los Angeles Latino Eye Study. Invest Ophthalmol Vis Sci. 2010; 51(6): 2872 -2877, doi: 10.1167/iovs.08-2956, indexed in Pubmed: 20089880.

20. Charlson ME, de Moraes CG, Link A, et al. Nocturnal systemic hypotension increases the risk of glaucoma progression. Ophthalmology. 2014; 121(10): 2004-2012, doi: 10.1016/j.ophtha.2014.04.016, indexed in Pubmed: 24869467.

21. Bowe A, Grünig M, Schubert J, et al. Circadian variation in arterial blood pressure and glaucomatous optic neuropathy: a systematic review and meta-analysis. Am J Hypertens. 2015; 28(9): 1077-1082, doi: 10.1093/ajh/hpv016, indexed in Pubmed: 25767134.

22. Millar-Craig MW, Bishop CN, Raftery EB. Circadian variation of blood-pressure. Lancet. 1978; 1(8068): 795-797, indexed in Pubmed: 85815.

23. Pillunat KR, Spoerl E, Jasper C, et al. Nocturnal blood pressure in primary open-angle glaucoma. Acta Ophthalmol. 2015; 93(8): e621-e626, doi: 10.1111/aos.12740, indexed in Pubmed: 25913492.

24. Flammer J, Pache M, Resink T. Vasospasm, its role in the pathogenesis of diseases with particular reference to the eye. Prog Retin Eye Res. 2001; 20(3): 319-349, indexed in Pubmed: 11286896.

25. Johnson PC. Autoregulation of blood flow. Circ Res. 1986; 59(5): 483-495, doi: 10.1161/01.res.59.5.483.

26. Topouzis F, Wilson MR, Harris A, et al. Association of open-angle glaucoma with perfusion pressure status in the Thessaloniki Eye Study. Am J Ophthalmol. 2013; 155(5): 843-851, doi: 10.1016/j. ajo.2012.12.007, indexed in Pubmed: 23394905.

27. Khawaja AP, Chan MPY, Broadway DC, et al. Systemic medication and intraocular pressure in a British population: the EPICNorfolk Eye Study. Ophthalmology. 2014; 121(8): 1501-1507, doi: 10.1016/j.ophtha.2014.02.009, indexed in Pubmed: 24702754.

28. Zheng W, Dryja TP, Wei Z, et al. Systemic Medication Associations with Presumed Advanced or Uncontrolled Primary Open-Angle Glaucoma. Ophthalmology. 2018; 125(7): 984-993, doi: 10.1016/j. ophtha.2018.01.007, indexed in Pubmed: 29433851.

29. Krasińska B, Karolczak-Kulesza M, Krasiński Z, et al. Effects of the time of antihypertensive drugs administration on the stage of primary open-angle glaucoma in patients with arterial hypertension. Blood Press. 2012; 21(4): 240-248, doi: 10.3109/08037051. 2012.666423, indexed in Pubmed: 22424547.

30. Whelton PK, Carey RM, Aronow WS, et al. 2017 ACC/AHA/ /AAPA/ABC/ACPM/AGS/APhA/ASH/ASPC/NMA/PCNA Guideline for the Prevention, Detection, Evaluation, and Management of High Blood Pressure in Adults: Executive Summary: A Report of the American College of Cardiology/American Heart Association Task Force on Clinical Practice Guidelines. J Am Coll Cardiol. 2018; 71(19): 2199-269.

31. De Moraes CG, Cioffi GA, Weinreb RN, et al. New recommendations for the treatment of systemic hypertension and their potential implications for glaucoma management. J Glaucoma. 2018; 27(7): 567-571, doi: 10.1097/IJG.0000000000000981, indexed in Pubmed: 29750712.

32. Drawz PE, Pajewski NM, Bates JT, et al. Effect of Intensive Versus Standard Clinic-Based Hypertension Management on Ambulatory Blood Pressure: Results From the SPRINT (Systolic Blood Pressure Intervention Trial) Ambulatory Blood Pressure Study. Hypertension. 2017; 69(1): 42-50, doi: 10.1161/HYPERTENSIONAHA.116.08076, indexed in Pubmed: 27849563.

33. Skrzypecki J, Ufnal M. Drug resistant hypertension: no simple way out. Kidney Blood Press Res. 2015; 40(1): 66-76, doi: 10.1159/000368483, indexed in Pubmed: 25791632.

34. Krum H, Schlaich MP, Sobotka PA, et al. Percutaneous renal denervation in patients with treatment-resistant hypertension: final 3-year report of the Symplicity HTN-1 study. Lancet. 2014; 383(9917): 622-629, doi: 10.1016/S0140-6736(13)62192-3, indexed in Pubmed: 24210779.

35. Bhatt DL, Kandzari DE, O'Neill WW, et al. A controlled trial of renal denervation for resistant hypertension. N Engl J Med. 2014; 370(15): 1393-1401, doi: 10.1056/NEJMoa1402670, indexed in Pubmed: 24678939.

36. Townsend RR, Mahfoud F, Kandzari DE, et al. Catheter-based renal denervation in patients with uncontrolled hypertension in the absence of antihypertensive medications (SPYRAL HTNOFF MED): a randomised, sham-controlled, proof-of-concept trial. Lancet. 2017; 390(10108): 2160-2170, doi: 10.1016/S01406736(17)32281-X, indexed in Pubmed: 28859944.

37. Brooks AM, Gillies WE. Ocular beta-blockers in glaucoma management. Clinical pharmacological aspects. Drugs Aging. 1992; 2(3): 208-221, doi: 10.2165/00002512-199202030-00005, indexed in Pubmed: 1351412.

38. Becker B, Pettit TH, Gay AJ. Topical epinephrine therapy of open-angel glaucoma. Arch Ophthalmol. 1961; 66: 219-225, indexed in Pubmed: 13688427.

39. Mansouri K, Weinreb RN, Liu JHK. Efficacy of a contact lens sensor for monitoring 24-h intraocular pressure related patterns. PLoS One. 2015; 10(5): e0125530, doi: 10.1371/journal. pone.0125530, indexed in Pubmed: 25942434.

40. Dunbar GE, Shen BY, Aref AA. The Sensimed Triggerfish contact lens sensor: efficacy, safety, and patient perspectives. Clin Ophthalmol. 2017; 11: 875-882, doi: 10.2147/OPTH.S109708, indexed in Pubmed: 28507427. 